\title{
PENGARUH HYDRAULIC LOADING RATE (HLR) TERHADAP PENGOLAHAN LEACHATE DENGAN MENGGUNAKAN METODA MULTI SOIL LAYERING (MSL)
}

\author{
THE EFFECT OF HYDRAULIC LOADING RATE (HLR) TOWARDS \\ LEACHATE PROCESSING USING MULTI SOIL LAYERING (MSL) \\ METHOD
}

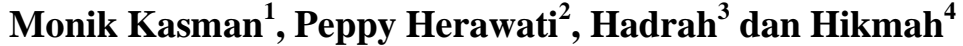 \\ Program Studi Teknik Lingkungan, Fakultas Teknik, Universitas Batanghari \\ Jl. Slamet Riyadi, Broni, Kota Jambi Telp./Fax. (0741)668280,

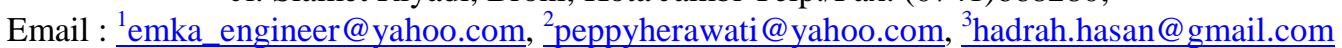

\begin{abstract}
ABSTRAK
Leachate atau lindi sampah berpotensi untuk mencemari air pemukaan dan air tanah. Hal ini diakibatkan degradasi biologis leachate menghasilkan pencemar berbahaya seperti zat organik dan logam berat. Penelitian ini bertujuan untuk mengamati efisiensi MSL dalam mereduksi pencemar yang terkandung dalam leachate. Pengamatan penelitian difokuskan pada pengaruh hydraulic loading rate (HLR) terhadap efisiensi reduksi pencemar, yang terdiri atas $250 \mathrm{l} / \mathrm{m}^{2}$.hari, 500 $1 / \mathrm{m}^{2}$.hari dan $1000 \mathrm{l} / \mathrm{m}^{2}$.hari. Penelitian ini dilakukan dengan cara mengalirkan secara gravitasi leachate Tempat Pemprosesan Akhir (TPA) Talang Gulo ke reaktor MSL berdimensi 15x50x50 $\mathrm{cm}$. Reaktor MSL terdiri atas lapisan impermeable dan lapisan permeabel. Lapisan impermeabel merupakan lapisan yang terdiri atas campuran tanah dan arang dengan rasio $2: 1$, serta lapisan permeabel terdiri atas lapisan zeolit berdiameter $0,25-0,5 \mathrm{~cm}$. Berdasarkan hasil penelitian, didapat bahwa MSL dapat menetralkan $\mathrm{pH}$ dan mereduksi konsentrasi pencemar COD, amoniak, besi $(\mathrm{Fe})$ dan warna. Efisiensi reduksi untuk semua pencemar berkisar $92 \%-99,966 \%$. Secara umum, HLR sangat mempengaruhi efisiensi reduksi, dimana makin rendah HLR maka makin rendah konsentrasi outlet serta makin tinggi efisiensi reduksi.
\end{abstract}

Kata kunci: Efisiensi reduksi, leachate, Multi Soil Layering (MSL)

\begin{abstract}
Landfill leachate is defined as any contaminated liquid effluent percolating through deposited waste and emitted within a landfill or dump site through external sources, of which its route of exposure and toxicity often remains unknown. Leachate migration could be potential source of run off and ground water pollutants. Hence, this research was objected to observe the effectivity of MSL method in reducing pollutant from leachate. It was focused on the effect of hydraulic loading rate (HLR) consisting $250 \mathrm{l} / \mathrm{m}^{2}$.day, $500 \mathrm{l} / \mathrm{m}^{2}$.day and $1000 \mathrm{l} / \mathrm{m}^{2}$.day on reduced pollutants including $\mathrm{pH}, \mathrm{COD}$, ammoniac, Fe and colour. It was conducted by introducing landfill leachate of Talang Gulo down to MSL reactor $15 \times 50 \times 50 \mathrm{~cm}$ by gravity force. MSL reactor was installed by unpermeable layer and permeable layer. Unpermeabel layer was composed by mixed soil and activated carbon by ratio 2:1, while permeable layer was zeolite with diameter 0,25-0,5 cm. Reduced pollutant efficiency ranging $92 \%-99,966 \%$. Based on the results, it was concluded that MSL method was able to reduce pollutant which was highly depends on HLR. Generally, HLR 250 $l / \mathrm{m}^{2}$.day was notably better performance in reducing all pollutants, where efficiency reduction increases as the HLR decreases.
\end{abstract}

Keywords: Reduction eficiency, leachate, Multi Soil Layering (MSL) 


\section{Pendahuluan}

Hasil sampingan dari proses pemusnahan akhir sampah di Tempat Pemprosesan Akhir (TPA) adalah air sampah yang lebih dikenal dengan lindi atau leachate. Leachate merupakan hasil perkolasi dan infiltrasi air sampah ke dalam tanah yang melarutkan dan membilas materi-materi terlarut termasuk materi organik hasil proses dekomposisi biologis (Tochbanoglous, 2009). Tingginya kandungan zat terlarut dan tersuspensi yang sangat halus dalam leachate berpotensi berpotensi mencemari air tanah dan air permukaan. Zat terlarut dan tersuspensi tersebut memicu peningkatan kesadahan, nitrit, nitrat, sulfat, besi, seng dan gas asam organik dan anorganik.

Beberapa penelitian telah dilakukan untuk mereduksi pencemar dalam leachate agar tidak membahayakan badan air penerima dan air tanah. Diantaranya, pengolahan leachate dengan adsorpsi (Kasman\&Ibrahim, 2011), anaerob (Adi dan Wahyu, 2009), fitoremediasi bambu air (Anam, 2011) dan model coagulation-biofilter (Sir dan Joko, 2009).

Dalam penelitian ini, pengolahan leachate dilakukan dengan metoda Multi Soil Layering (MSL). Kelebihan MSL, selain ekonomis, tidak membutuhkan lahan luas juga mudah dalam pengoperasian dan memanfaatkan kearifan lokal. MSL merupakan salah satu metoda pengolahan air limbah dan air bersih yang mengoptimalisasi proses filtrasi, adsorpsi dan proses membran dalam suatu sistem reaktor MSL (Wakatsuki et al, 2003). Reaktor MSL terdiri atas lapisan impermeabel yaitu campuran tanah, arang dan material organik serta lapisan permeabel yaitu kerikil atau jenis batuan lain. Material yang digunakan dalam instalasi reaktor MSL tersedia melimpah di Indonesia, sehingga sangat direkomendasikan untuk diimplementasikan.

Diantara hasil positif dari implementasi metoda MSL untuk pengolahan limbah cair domestik dan industri dilaporkan oleh Kasman (2004). Dari penelitian tersebut, didapatkan hasil reduksi pencemar lebih dari $90 \%$. Fokus penelitian ini adalah mengamati pengaruh laju pembebanan hidraulis atau hydraulic loading rate (HLR) terhadap penetralan $\mathrm{pH}$ dan efisiensi reduksi pencemar dalam MSL, meliputi COD, amoniak,Fe (besi) dan warna.

\section{Metodologi Penelitian}

\subsection{Alat dan Bahan}

Reaktor MSL (gambar 1) yang akan didesain terbuat dari akrilik dengan dimensi 15 x 50 x $50 \mathrm{~cm}$ yang dilengkapi dengan pipa inlet $1 / 2$ inch, dan pipa outlet $1 / 2$ inch. Komposisi MSL terdiri atas lapisan campuran tanah sebagai media unpermeabel dan lapisan zeolit sebagai media permeabel berukuran $0.25-0.5 \mathrm{~cm}$. Komposisi lapisan campuran tanah terdiri atas tanah andesol dan arang dengan rasio 2:1. Lapisan permeabel dan unpermeabel disusun berselang-seling menyerupai susunan batu bata.

Lapisan dasar reaktor MSL adalah batu pecah berdiameter $1-3 \mathrm{~cm}$ dengan ketinggian $5 \mathrm{~cm}$ disusun dan ditutup permukaannya dengan jaring plastik. Lapisan kedua, diisi dengan zeolit dengan ketinggian $5 \mathrm{~cm}$. Pada lapisan ketiga dibuat blok campuran tanah yang dipasang sejajar pada jarak masing-masingnya $4 \mathrm{~cm}$. Kemudian lapisan selanjutnya diisi dengan zeolit setinggi $3 \mathrm{~cm}$. Lapisan-lapisan lain diisikan dengan cara yang sama sampai membentuk beberapa lapis blok-blok campuran tanah, lalu ditutupi dengan jaring plastik dan diatas jaring plastik tersebut dilapisi dengan lapisan zeolit setinggi $3 \mathrm{~cm}$. Instalasi reaktor MSL dilengkapi dengan bak penampung leachate baku (inlet) dan bak penampung hasil olahan leachate (outlet). 


\subsection{Sampel leachate}

Sampel leachate yang belum diolah (leachate baku), diperoleh dari bak penampung leachate TPA Talang Gulo Jambi, secara grab sampling (sampel sesaat). Satu kali eksperimen, sampel yang dialirkan ke reaktor MSL adalah 20 liter. Sampel yang diambil disimpan dalam wadah dirigen plastik dan segera digunakan. Karakterisasi awal sampel leachate dilakukan untuk mengetahui besar konsentrasi pencemar yang terdapat dalam leachate yang akan diolah. Secara fisis diketahui leachate TPA Talang Gulo berwarna coklat kehitaman (gambar 2) dan sangat berbau. Kandungan Parameter Pencemar TPA Talang Gulo Jambi, serta perbandingan PerMen RI No. 82 Tahun 2001 Tentang Pengelolaan Kualitas Air dan Pengendalian Pencemaran Air dapat dilihat di Tabel 1. Perbandingan visual antara leachate baku dan hasil olahannya dapat dilihat pada gambar berikut:.

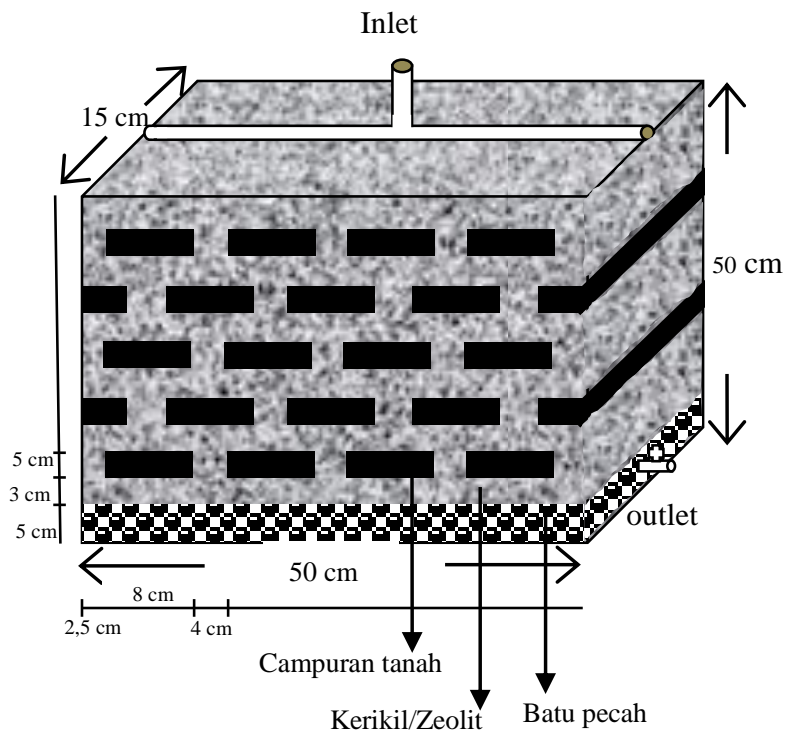

Gambar 1. Reaktor MSL

Tabel 1. Perbandingan konsentrasi leachate baku dengan Permen RI No.82/2001

\begin{tabular}{cccc}
\hline Parameter & Satuan & PerMen RI No.82/2001 & $\begin{array}{c}\text { TPA Talang Gulo } \\
\text { Jambi }\end{array}$ \\
\hline COD & $\mathrm{mg} / \mathrm{l}$ & 100 & 2261 \\
Amoniak & $\mathrm{mg} / \mathrm{l}$ & 0.5 & 676.2 \\
TSS & $\mathrm{mg} / \mathrm{l}$ & $*$ & 0.0121 \\
Fe & $\mathrm{mg} / \mathrm{l}$ & 0,3 & 5.2268 \\
Sulfat & $\mathrm{mg} / \mathrm{l}$ & 400 & 0.016 \\
Cl & $\mathrm{mg} / \mathrm{l}$ & 600 & 900 \\
Warna & $\mathrm{S} . P t C o$ & $*$ & 5000 \\
pH & - & $6.5-8.5$ & 5.55 \\
\hline
\end{tabular}

*tidak tercantum dalam Permen RI No.82/2001

Analisis parameter menggunakan metoda yang mengacu pada APHA (American Public Health Association). Analisis pH menggunakan $\mathrm{pH}$ Meter; COD menggunakan metoda kolorimetrik dengan spektrofotometer; amoniak menggunakan Metoda Nessler; Fe (Besi) menggunakan AAS dan warna menggunakan metoda spektrofotometer. Dari Tabel 1, terlihat bahwa leachate TPA Talang Gulo Jambi bersifat asam, dengan konsentrasi COD, amoniak, Fe, $\mathrm{Cl}$ dan warna yang melebihi ambang batas PerMen RI no. 82 tahun 
2001. Ditinjau dari konsentrasi COD, maka leachate dikategorikan sebagai leachate tua (Alvarez-Vazquez et al., 2004).

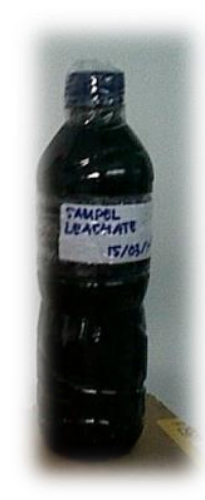

a

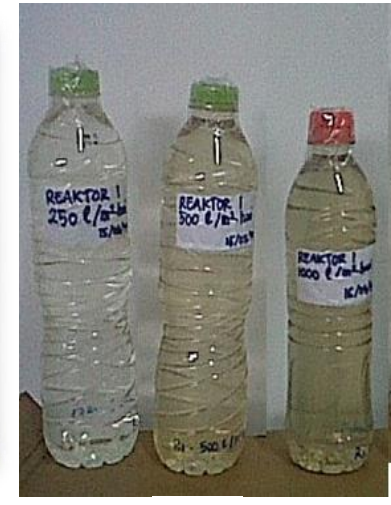

b

Gambar 2. Sampel leachate TPA Talang Gulo (a) dan hasil pengolahan leachate (b)

\subsection{Prosedur}

Pada penelitian ini, leachate baku dialirkan secara gravitasi pada reaktor MSL dengan variasi 3 HLR. Pengaruh variasi hydraulic loading rate (HLR) atau laju pembebanan hidrolis meliputi $250 \mathrm{l} / \mathrm{m}^{2}$.hari, $500 \mathrm{l} / \mathrm{m}^{2}$.hari dan $1000 \mathrm{l} / \mathrm{m}^{2}$.hari diamati.

\section{Hasil dan Pembahasan}

\subsection{Debit pengolahan dan waktu detensi}

Leachate dialirkan dengan Hydraulic Loading Rate (HLR) 250 1/ $\mathrm{m}^{2}$.hari, 500 $1 / \mathrm{m}^{2}$.hari dan $1000 \mathrm{l} / \mathrm{m}^{2}$.hari. Hydraulic loading rate adalah besarnya laju alir pembebanan hidrolis (HLR) dalam leachate terhadap suatu bidang permukaan dalam satuan waktu tertentu. Dalam aplikasinya HLR digunakan untuk menentukan debit atau beban leachate yang akan dialirkan ke reaktor MSL dalam satuan waktu tertentu, misalnya dinyatakan dalam ml/menit. Pada HLR $2501 / \mathrm{m}^{2}$.hari, $500 \mathrm{l} / \mathrm{m}^{2}$.hari dan $1000 \mathrm{l} / \mathrm{m}^{2}$.hari debit leachate secara berurut adalah $13 \mathrm{ml} /$ menit, $26 \mathrm{ml} /$ menit dan $52 \mathrm{ml} /$ menit. Waktu detensi secara berurut pada HLR $250 \mathrm{l} / \mathrm{m}^{2}$.hari, $500 \mathrm{l} / \mathrm{m}^{2}$.hari dan $1000 \mathrm{l} / \mathrm{m}^{2}$.hari adalah 40 menit, 27 menit dan 12 menit.

\subsection{Pengaruh HLR terhadap Efisiensi Reduksi Parameter Pencemar Leachate}

Leachate baku ditampung dan dihomogenkan dengan cara diaduk manual sebelum dialirkan ke reaktor MSL. Leachate dialirkan secara gravitasi atas ke bawah (gravity downflow system). Eksperimen dilakukan secara batch (non kontinu) dengan HLR 250 $1 / \mathrm{m}^{2}$.hari, $500 \mathrm{l} / \mathrm{m}^{2}$.hari dan $1000 \mathrm{l} / \mathrm{m}^{2}$.hari. Hasil analisis pengolahan leachate dengan metoda MSL disajikan pada Tabel 2.

\section{Penetralan $\mathrm{pH}$}

Leachate baku bersifat asam dengan $\mathrm{pH}$ rata-rata 5.55. Tingginya kandungan asam lemak dan senyawa organik merupakan faktor utama yang menyebabkan keasaman leachate baku (Ginting, 2007 dalam Putra, 2011). Setelah mengalami pengolahan di rektor MSL, kondisi leachate menjadi netral. Hal ini diperlihatkan pada gambar 3, pH leachate setelah diolah (outlet) pada ketiga HLR adalah netral tidak melebihi baku mutu $(6-9)$. Pada HLR $2501 / \mathrm{m}^{2}$.hari, $\mathrm{pH}$ mendekati 7 , nilai $\mathrm{pH}$ makin tinggi saat HLR makin tinggi. 
HLR yang lebih rendah ternyata lebih baik dalam proses penetralan $\mathrm{pH}$. Waktu kontak yang lebih lama dan sifat alami tanah dan zeolit menjadi faktor yang mempengaruhi proses penetralan $\mathrm{pH}$.

Tabel 2. Hasil analisis pengolahan leachate TPA Talang Gulo dengan MSL

\begin{tabular}{|c|c|c|c|c|}
\hline \multirow{2}{*}{ Parameter } & \multirow{2}{*}{ Satuan } & \multicolumn{3}{|c|}{ HLR (l/m².hari) } \\
\hline & & 250 & 500 & 1000 \\
\hline \multicolumn{5}{|c|}{ pH } \\
\hline Inlet & $\mathrm{mg} / \mathrm{l}$ & 5.55 & 5.55 & 5.55 \\
\hline Outlet & $\mathrm{mg} / \mathrm{l}$ & 7.16 & 7.56 & 7.76 \\
\hline \multicolumn{5}{|c|}{ COD } \\
\hline Inlet & $\mathrm{mg} / \mathrm{l}$ & 2261 & 2261 & 2261 \\
\hline Outlet & $\mathrm{mg} / \mathrm{l}$ & 73 & 89 & 141 \\
\hline Efisiensi & $\%$ & 96.771 & 96.064 & 93.764 \\
\hline \multicolumn{5}{|c|}{ Amoniak } \\
\hline Inlet & $\mathrm{mg} / \mathrm{l}$ & 676.2 & 676,2 & 676.2 \\
\hline Outlet & $\mathrm{mg} / \mathrm{l}$ & 0.901 & 0.458 & 0.229 \\
\hline Efisiensi & $\%$ & 99.867 & 99.932 & 99.966 \\
\hline \multicolumn{5}{|c|}{$\mathrm{Fe}$} \\
\hline Inlet & $\mathrm{mg} / \mathrm{l}$ & 5.227 & 5.227 & 5.227 \\
\hline Outlet & $\mathrm{mg} / \mathrm{l}$ & 0.08 & 0.038 & 0.443 \\
\hline Efisiensi & $\%$ & 99.00 & 99.28 & 91.52 \\
\hline \multicolumn{5}{|c|}{ Warna } \\
\hline Inlet & S.PtCo & 5000 & 5000 & 5000 \\
\hline Outlet & S.PtCo & 200 & 400 & 400 \\
\hline Efisiensi & $\%$ & 96 & 92 & 92 \\
\hline
\end{tabular}

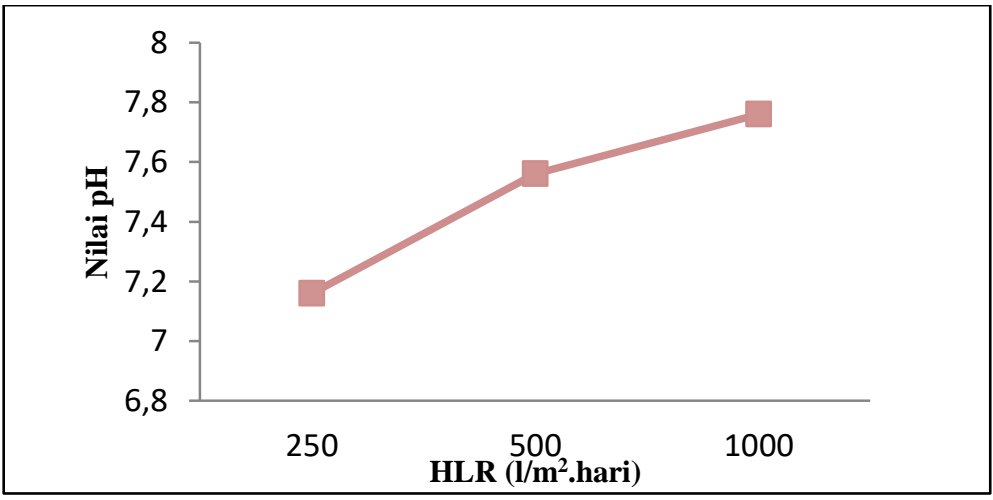

Gambar 3. Pengaruh HRL Terhadap Nilai pH

Kapasitas tukar kation zeolit yang tinggi dan bidang permukaan penyerapan yang luas akan mempermudah penguraian asam lemak dan senyawa organik terlarut (Halim et al, 2010).

\section{Efisiensi Reduksi COD}

COD menggambarkan jumlah senyawa organik yang terdapat dalam leachate. Dari gambar 4 terlihat kurva konsentrasi COD dimana terjadi penurunan yang cukup tinggi. Efisiensi reduksi parameter COD pada pengolahan leachate pada semua HLR cenderung turun jika HLR dinaikkan. Secara berurut efisiensi reduksi untuk HLR 250 1/m².hari, 500 
$1 / \mathrm{m}^{2}$.hari, dan $1000 \mathrm{l} / \mathrm{m}^{2}$.hari adalah $96.771 \%, 96.064 \%$, dan $93.764 \%$. HLR yang rendah menyebabkan waktu kontak yang lebih lama antara leachate baku dengan media MSL sehingga reduksi COD makin tinggi (Sato et al, 2010). Berdasarkan hasil analisis dan pengamatan, MSL terbukti efektif untuk menyisihkan parameter pencemar COD.

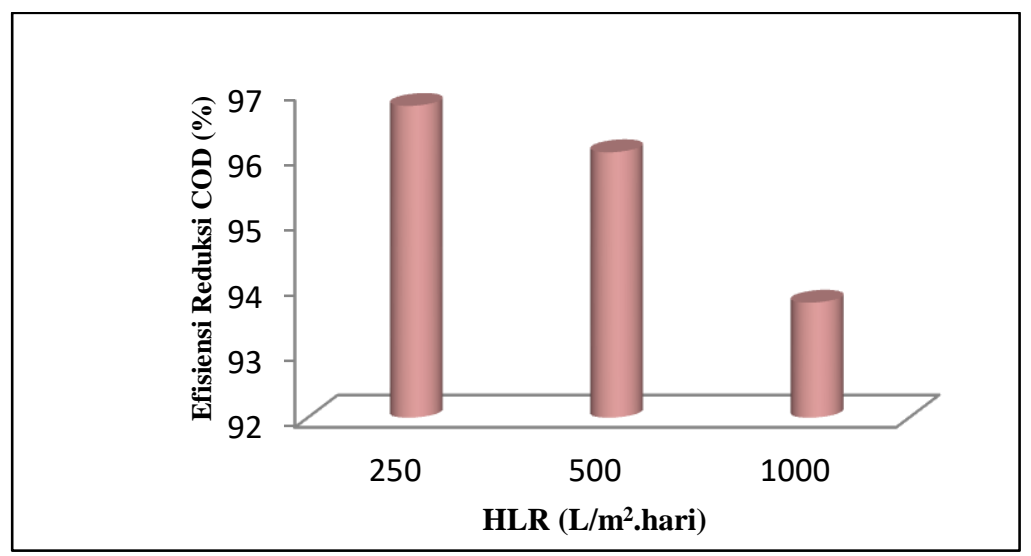

Gambar 4. Pengaruh HLR Terhadap Reduksi COD

Hasil yang sama juga dilaporkan oleh Kasman (2004) dan Kasman et al (2014), parameter COD dapat direduksi hingga 90\%. Sama halnya dengan penetralan pH, penguraian asam lemak dan senyawa organik pada kombinasi antara kapasitas tukar kation zeolit yang tinggi dan luas permukaan bidang adsorban pada campuran tanah merupakan faktor utama dalam penurunan konsentrasi COD (Halim et al, 2010; Chen et al, 2011).

\section{Efisiensi Reduksi Amoniak}

Amoniak juga memberikan gambaran jumlah senyawa organik yang terdapat dalam leachate. Setelah mengalami pengolahan, terlihat MSL efektif dalam menurunkan konsentrasi amoniak. Konsentrasi Amoniak setelah pengolahan (outlet) dengan HLR 250 $1 / \mathrm{m}^{2}$.hari, $500 \mathrm{l} / \mathrm{m}^{2}$.hari, $1000 \mathrm{l} / \mathrm{m}^{2}$.hari secara berurut yaitu $0.901 \mathrm{mg} / 1,0.458 \mathrm{mg} / \mathrm{l}$, dan $0.229 \mathrm{mg} / \mathrm{l}$. Berdasarkan gambar 5, dari hasil penelitian didapatkan bahwa HLR tidak mempengaruhi reduksi amoniak. Efisiensi reduksi pada pengolahan pada semua HLR terlihat hampir sama yaitu secara berurut pada $250 \mathrm{1} / \mathrm{m}^{2}$.hari, $500 \mathrm{l} / \mathrm{m}^{2}$.hari dan 1000 $1 / \mathrm{m}^{2}$.hari adalah $99.867 \%, 99.932 \%$, dan $99.966 \%$.

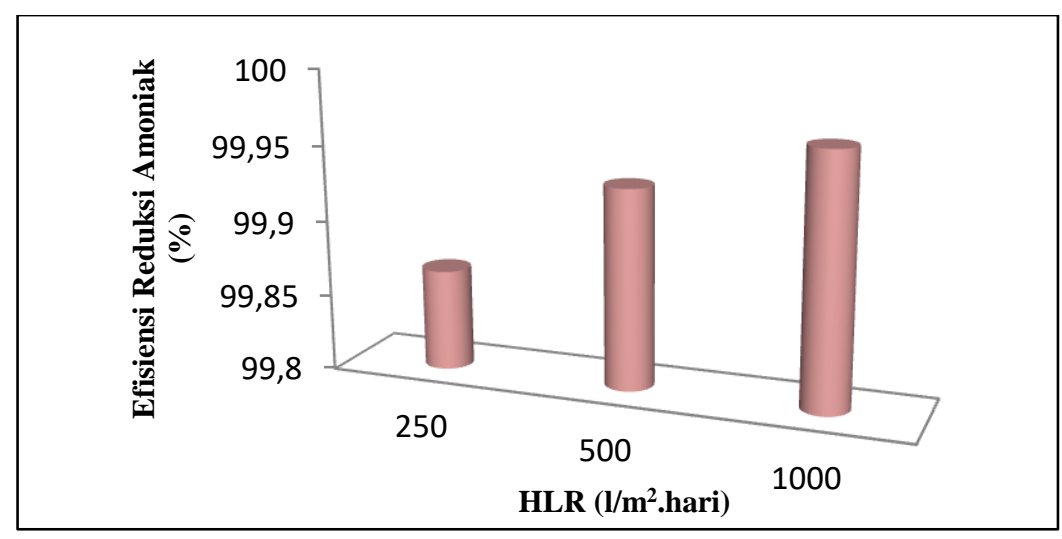

Gambar 5. Pengaruh HLR Terhadap Reduksi Amoniak

Efisiensi Reduksi Fe (Besi) 
Konsentrasi Fe yang tersisihkan makin tinggi pada HLR yang lebih rendah (Tabel 2). Pengaruh HLR pada reduksi parameter Fe dapat dilihat lebih jelas pada gambar 6 berikut. Efisiensi reduksi pada pengolahan dengan HLR $250 \mathrm{l} / \mathrm{m}^{2}$.hari, $500 \mathrm{l} / \mathrm{m}^{2}$.hari, dan 1000 $1 / \mathrm{m}^{2}$.hari adalah $99.00 \%, 99.279 \%$ dan $91.523 \%$. Syafnil (2008) juga menyatakan bahwa HLR sangat berpengaruh pada reduksi Fe di leachate, dimana dengan variasi HLR 300 $1 / \mathrm{m}^{2}$.hari hingga $1500 \mathrm{l} / \mathrm{m}^{2}$.hari, Fe dapat tersisih hingga $91.94 \%$.

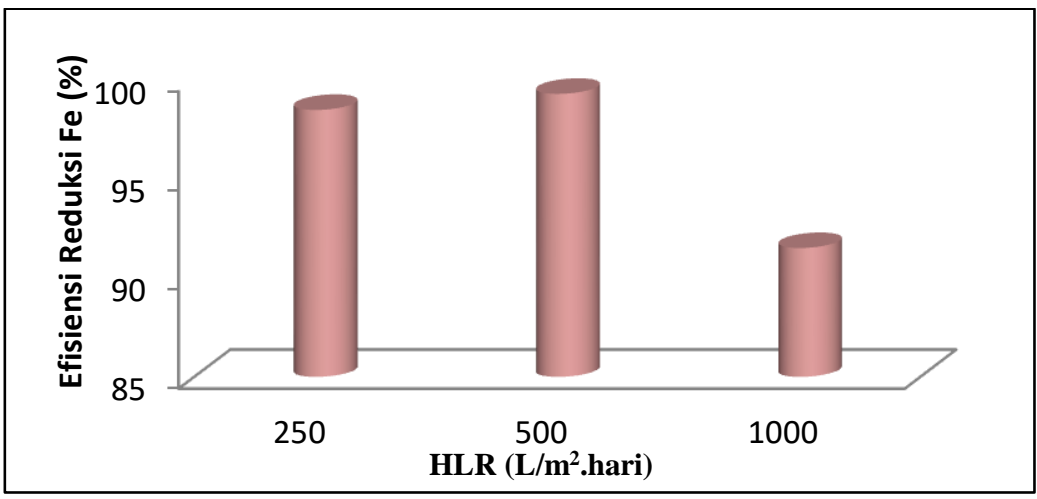

Efisiensi Reduksi Warna

Gambar 6. Pengaruh HLR Terhadap Reduksi Fe

Konsentrasi warna outlet pada semua HLR dan kondisi proses dapat dilihat pada kurva di gambar 7, konsentrasi Warna dengan HLR $2501 / \mathrm{m}^{2}$.hari, $500 \mathrm{l} / \mathrm{m}^{2}$.hari, dan 1000 $1 / \mathrm{m}^{2}$.hari secara berurut $96 \%, 92 \%$ dan $92 \%$. Perubahan warna sangat dipengaruhi oleh perubahan $\mathrm{pH}$ Pada penelitian didapatkan penetralan $\mathrm{pH}$ dicapai pada nilai antara 7 dan 8 . Hal ini sesuai dengan penelitian Aziz et al (2007) bahwa reduksi maksimum warna dicapai pada $\mathrm{pH}$ antara 4 dan 12. Makin rendah HLR menyebabkan waktu kontak leachate makin lama dengan media MSL sehingga meningkatkan reduksi warna (Sato et al, 2010).

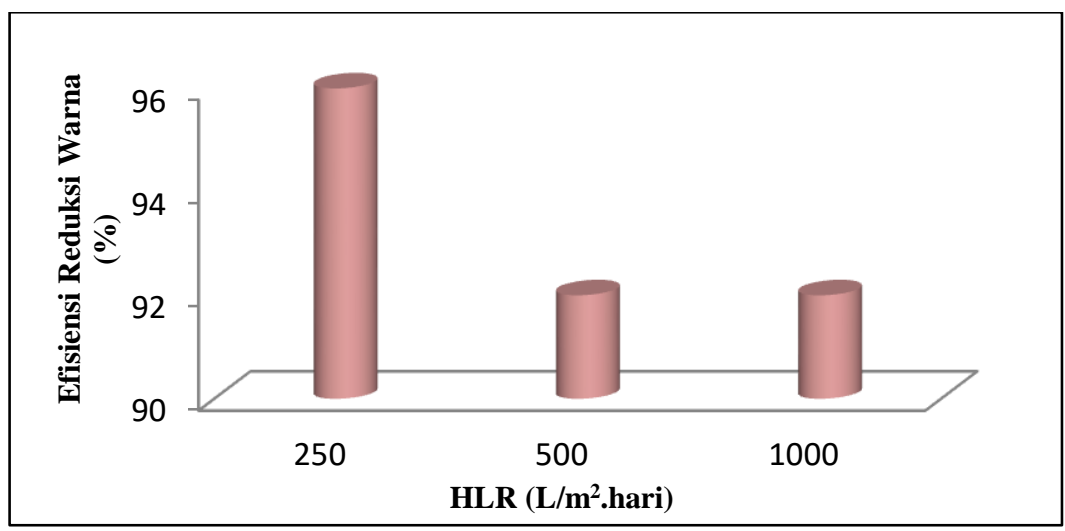

Gambar 7. Pengaruh HLR Terhadap Reduksi Warna

\section{Kesimpulan}

Dari hasil penelitian yang dilakukan, dapat dikemukakan beberapa kesimpulan sebagai berikut:

1. Persentase reduksi tertinggi untuk COD, amoniak, Fe dan warna adalah $96.771 \%$, 99.966\%, 99.279\% dan 96.53\% serta nilai $\mathrm{pH}$ berkisar 7,00.

2. Kecuali pada reduksi amoniak, ternyata dari hasil penelitian HLR sangat berpengaruh terhadap reduksi parameter pencemar dalam leachate. Makin rendah HLR, maka makin tinggi efisiensi reduksi pencemar. 


\section{Daftar Pustaka}

American Public Health Association (APHA). 1995. Standard Methods for the Examination of Water and Wastewater, Ed.19th, Washington, DC.

Chen, X., Sato, K., Wakatsuki, T., and Masunaga, T. 2011. Effect of structural difference on wastewater treatment efficiency in multi-soil-layering systems: Relationship between soil mixture block size and removal efficiency of selected contaminants. Soil Science and Plant Nutrition, Vol.53, No. 2, 206-214.

Kasman, Monik. 2004. Studi Pengolahan Limbah Cari Industri Keripik Ubi Kayu (Manihot Utilissima) dengan Metoda Multi Soil Layering (MSL). Tugas Akhir, Fakultas Teknik Universitas Andalas, Padang,

Kasman, M., Herawati, P., dan Hikmah. 2014. Pengolahan Leachate dengan Menggunakan Multi Soil Layering (MSL). Jurnal Ilmiah Universitas Batanghari, Vol.14 No.3, 107-112.

Per.Men Kesehatan RI. Nomor. 82/Tahun 2001. Tentang Pengelolaan Kualitas Air dan Pengendalian Pencemaran Air.

Putra, A. 2011. Pengolahan Limbah Cair PT. Bumi Sarimas Menuju Air Layak MInum dengan Metoda MSL (Multi Soil Layering) yang Dicampurkan Sekam Padi Thesis Pascasarjana, Universitas Andalas, Padang,.

Sato, K., Iwashima, N., Matsumoto, T., Wakatsuki, T., and Masunaga, T. 2010. Wastewater treatment processes and mechanisms of organic matter, phosphorus, and nitrogen removal in a multi-soil-layering system. Proceeding of 19th World Congress of Soil Science, Soil Solutions for a Changing World, 85-88.

Tchobanoglous, G \& Burton, F. L. 1991. Wastewater Engineering, Treatment, Disposal and Reuse, Ed. $3^{\text {rd }}$, New York: McGraw-Hill.

Wakatsuki, T., et al. 2003. High Performance and N \& P Removal on-Site Wastewater Treatment System by Multi Soil Layering Method. Water Science Technology, 27.

Alvarez-Vazquez, H., Jefferson, B., \& Judd, S. 2004. Membrane bioreactors vs conventional biological treatment of landfill leachate: a brief review. Journal of Chemical Technology and Biotechnology, 79, 1043-1048.

Halim, A.A., et al. 2010. Ammoniacal nitrogen and COD removal from semi-aerobic landfill leachate using a composite adsorbent: Fixed bed column adsorption performance. Journal of Hazardous Materials, Vol. 175, 960-964.

Aziz, H.A, et al. 2007. Colour removal from landfill leachate by coagulation and flocculation processes. Bioresource Technology, Vol.98, 218-220. 